\title{
Design of tunnel drier for the non-centrifugal sugar industry
}

\author{
S. P. Raj ${ }^{1 *}$, B. Sravya ${ }^{1 \$}$, M. Srinivas ${ }^{1 \#}$, Reddy $\mathrm{KS}^{2}$ \\ ${ }^{1}$ Department of mechanical engineering, BITS Pilani, Hyderabad Campus, India \\ ${ }^{2}$ Heat Transfer and Thermal Power Laboratory, Department of mechanical engineering, IIT \\ Madras, Chennai, ksreddy@iitm.ac.in \\ *Corresponding author.Tel.: +91 9618331321.E-mail: p20170445@hyderabad.bits- \\ pilani.ac.in ,\$p20180033@hyderabad.bits-pilani.ac.in, ${ }^{*}$ morasrini@hyderabad.bits- \\ pilani.ac.in
}

\begin{abstract}
The quality and shelf-life of NCS (Non-centrifugal sugar) mainly depend on the moisture content present in it. NCS formed by the current practice of open sun drying contains moisture substantially greater than the acceptable level of $3 \%$. This paper presents the work taken up to design a tunnel dryer to attain require moisture content in granular NCS for various load conditions. Initially, an experimental investigation had been carried out on a laboratory scale dryer to achieve require moisture content $(\leq 3 \%)$ for various load conditions. This experimental data was used for validating two drying models and found that one of the models is best suitable for designing an industrial-scale dryer. For various load conditions on each tray and dryer exit temperature, nine different cases were arrived at. The number of trucks, trays, drying time and energy requirements were computed using the suitable theoretical model. Tunnel dryer with a length of $18 \mathrm{~m}$, a height of $1.2 \mathrm{~m}$, a width of $1 \mathrm{~m}$, number of trucks of 18 and 24 number of trays on each truck was found to be the suitable dryer to dry 1 tone of NCS based on the minimum energy requirement of $176.49 \mathrm{MJ}$, and a minimum drying time of 68 minutes.
\end{abstract}

\section{Nomenclature}

\begin{tabular}{|llll|}
\hline$a$ & Distance between the trays $(\mathrm{m})$ & $Q_{\text {air }}$ & Air flow rate $\left(\mathrm{m}^{3} / \mathrm{s}\right)$ \\
$b$ & Width of the tray $(\mathrm{m})$ & $T_{\infty}$ & Temperature of air at the inlet of the dryer \\
$C_{N C S}$ & $\begin{array}{l}\text { Specific heat of the NCS granules } \\
(\mathrm{kJ} / \mathrm{kg}-\mathrm{K})\end{array}$ & $T_{i}$ & Initial NCS bed temperature \\
& Specific heat of the air $(\mathrm{kJ} / \mathrm{kg}-\mathrm{K})$ & $V_{\text {air }}$ & Velocity of air above each tray $(\mathrm{m} / \mathrm{s})$ \\
$C_{a i r}$ & Specific heat of water $(\mathrm{kJ} / \mathrm{kg}-\mathrm{K})$ & $X_{c}$ & Critical moisture content $(\%)$ \\
$C_{p}$ & Rate of air mass flux & $X_{I}$ & Equilibrium moisture content $(\%)$ \\
$G$ & Heat transfer coefficient $\left(\mathrm{W} / \mathrm{m}^{2} \mathrm{~K}\right)$ & $X$ & Instantaneous moisture content $(\%)$ \\
$h$ & Latent heat of moisture & $\rho_{a i r}$ & Density of air $\left(\mathrm{kg} / \mathrm{m}^{3}\right)$ \\
$h_{f g}$ & &
\end{tabular}




\begin{tabular}{|llll|}
\hline$m_{w j}$ & Equivalent mass of moisture in terms of & $\Delta p$ & Pressure drop in the duct \\
& NCS $(\mathrm{kg})$ \\
$m_{w}$ & Amount of moisture removed $(\mathrm{kg})$ & & \\
$\dot{m}$ & drying rate $(\mathrm{kg} / \mathrm{s})$ \\
$m_{N C S}$ & Mass of the NCS sample $(\mathrm{kg})$ & \\
\hline
\end{tabular}

\section{Introduction}

Non-centrifugal sugar (NCS), popularly referred to as jaggery, is a traditional and unrefined sugar produced by sugarcane juice concentration. It is a rich mixture of essential nutrients and is therefore considered as the healthiest kind of sugar for human consumption [1]. The processing of NCS is a continuous process of heat and mass transfer involving clarification, boiling and concentration of sugarcane juice [2]. A traditional NCS production unit typically consists of a sugarcane juice crusher, an underground furnace fitted with single or multi-pan systems, where the water is evaporated to concentrate the juice to produce NCS [3] [4]. In India, a large portion of the NCS is manufactured in small-scale cottage level industry [5]. Figure 1 shows the basic production process of NCS production.

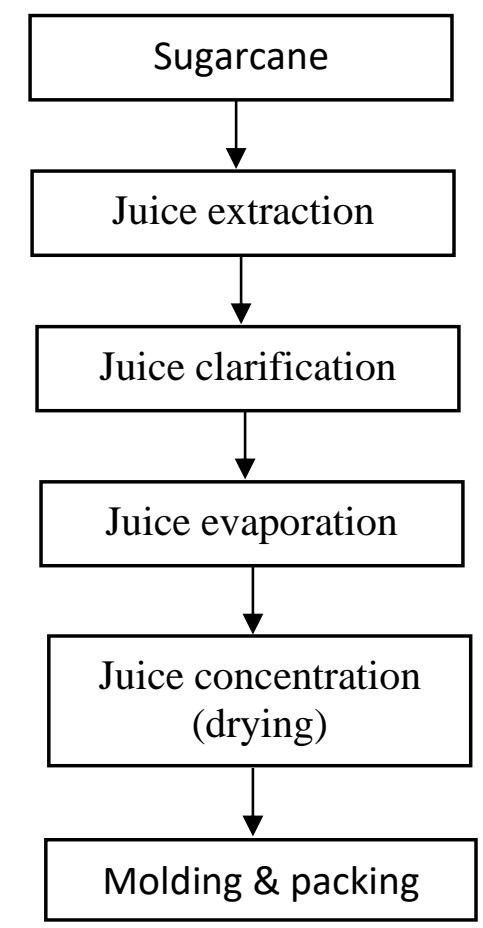

Figure 1. Basic production process NCS production [3]

NCS production in India starts in the month of October and continuous till mid of May and is stored for the rest of the year [6]. The quality of stored NCS depends mostly on the moisture content. The higher moisture in NCS is favorable for the inversion and growth of different types of fungi and bacteria resulting in a change in taste and colour [7]. The growth of microorganisms and deterioration of NCS is maximum at $10 \%$ moisture content and $30^{\circ} \mathrm{C}$ 
temperature [8]. The freshly prepared NCS contents moisture about 13 to $15 \%$ but preferably is below 3\% for NCS storage for longer shelf-life [9]. Further, it has become a prerequisite for the industry to maintain the optimal level of moisture content in NCS to meet the standards and requirements in food hygiene and handling such as packing, transportation and distribution [10]. Drying of NCS is one of the processes to remove the excess moisture content and further increases the shelf-life of NCS during storing. It is a heat and mass transfer phenomenon in which the heat energy is transferred from the surrounding to the NCS surface in different heat transfer modes. Some part of heat supplied is used for sensible heating to increase the surface temperature of NCS and a part is used for the latent heat of vaporisation to remove the moisture present in the interior of NCS. The amount of moisture removed from the NCS depends upon the induced vapour pressure difference between the NCS surface and the surrounding medium [11].

Depending upon the method of drying, drying may be classified as open sun drying or controlled drying [12]. To have better control over the drying rate, controlled drying would be a better option than open sun drying that depends on weather conditions. However, in most of the conventional NCS plant, open sun drying is the major practice for drying NCS. In this process of drying, the NCS syrup formed after the concentration of sugarcane juice is moved from the furnace and is continuously stirred with flat wooden stirrers for uniform cooling by natural air. Then the obtained semi solidified syrup is transferred into aluminum mould or aluminium tray to form solid NCS or granular NCS. The granular NCS is formed by the action of severe shearing of semi solidified syrup in aluminium tray using wooden or stainless steel scrappers. The moisture content in solid NCS and granular NCS formed by this process ranges above $3 \%$, which is not preferable for longer storage as it affects the quality and shelf-life of NCS [13]. Every year, it is noted that more than $10 \%$ of NCS produced in India worth $\$ 0.6$ million is lost due to moisture deterioration [14]. Therefore, to achieve a preferable moisture content (that is below 3\%), the drying rate should be controlled instead of depending on the weather conditions. To have better control over the drying rate, a control dryer is to be designed and analysed as per the requirement to remove moisture in NCS.

Controlled dryers are available in a wide variety to meet the requirement of the food industry. The selection of dryers for a particular application depends mainly on the amount of moisture to be removed, the scale of operation, method of heat energy supplied and cost [15]. The dryers that are commonly used in food industries are tray dryers, tunnel dryers, drum dryers, fluidized bed spray dryers, flash dryers, rotary dryers, belt dryers, vacuum dryers, and freeze dryers. 
Among these dryers, the tunnel dryer is most extensively used because of its simple and economic design and most importantly it produces uniform drying [16]. It can remove moisture uniformly from the material with low moisture content to a material with high moisture content without any deterioration. Unlike other dryers, the operation is simple and produces slow and uniform drying [17].

Tunnel dryers are considered as the development of a tray dryer. Figure 2 shows the schematic diagram of tunnel dyer. The trays arranged on the trolleys called trucks. The dryer contains several such trucks/trolleys, each of which behaves as a separate batch tray dryer. The material to be dried is placed uniformly on each tray. Then the air is blown over the trays in the tunnel using the blower for proper circulation [16]. Forced convection heating takes place to remove moisture from the material placed in trays. A truck of dried material is removed from the dry end of the tunnel and the remaining trucks are pushed forward along the truck length and the truck of wet material is rolled into the vacant space at the wet end of the dryer [18].

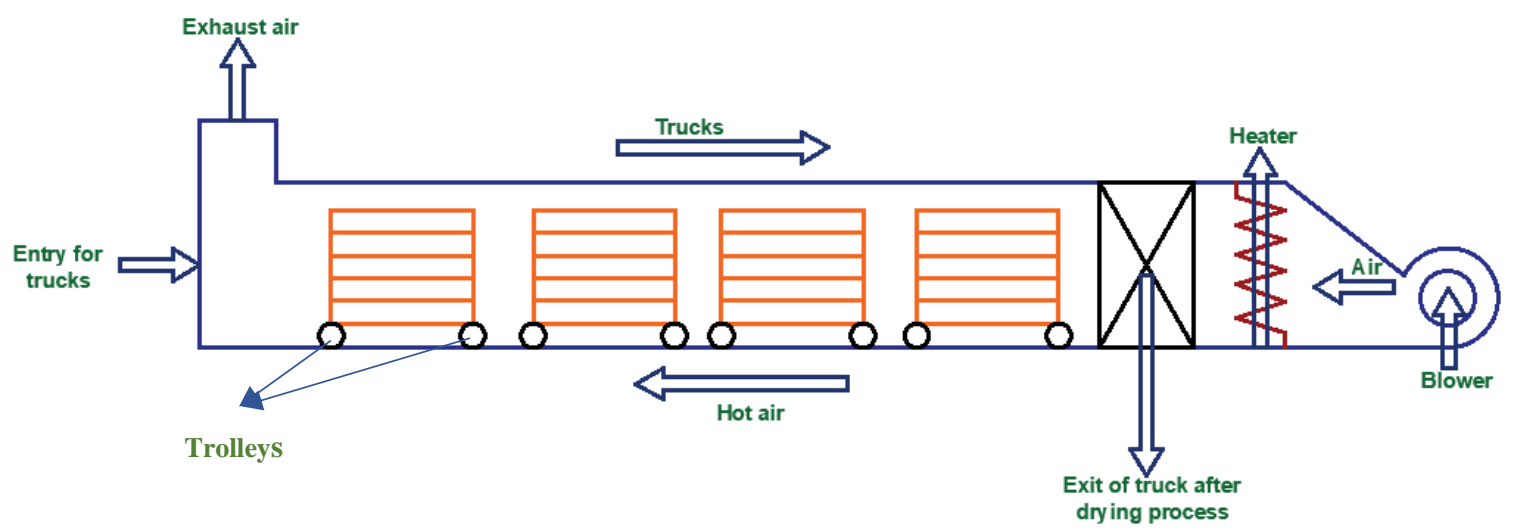

Figure 2. Schematic diagram of tunnel dyer to designed for drying NCS granules

This paper presents the works taken up to design a tunnel dryer to attain moisture content below $3 \%$ in granular NCS for various load conditions. Initially, a laboratory-scale dryer is considered and the experimental analysis is carried out for drying NCS. This experimental data is used for validating the drying models that were considered to design a suitable industrial tunnel dryer for removing excess moisture in NCS, to produce quality NCS and can be retained during storing.

\section{Materials and methods}

The schematic diagram of the methodology adopted for designing an industrial dryer to achieve a moisture content below 3\% in granular NCS is shown in Figure 3. The following sections describe the methodology adopted. 


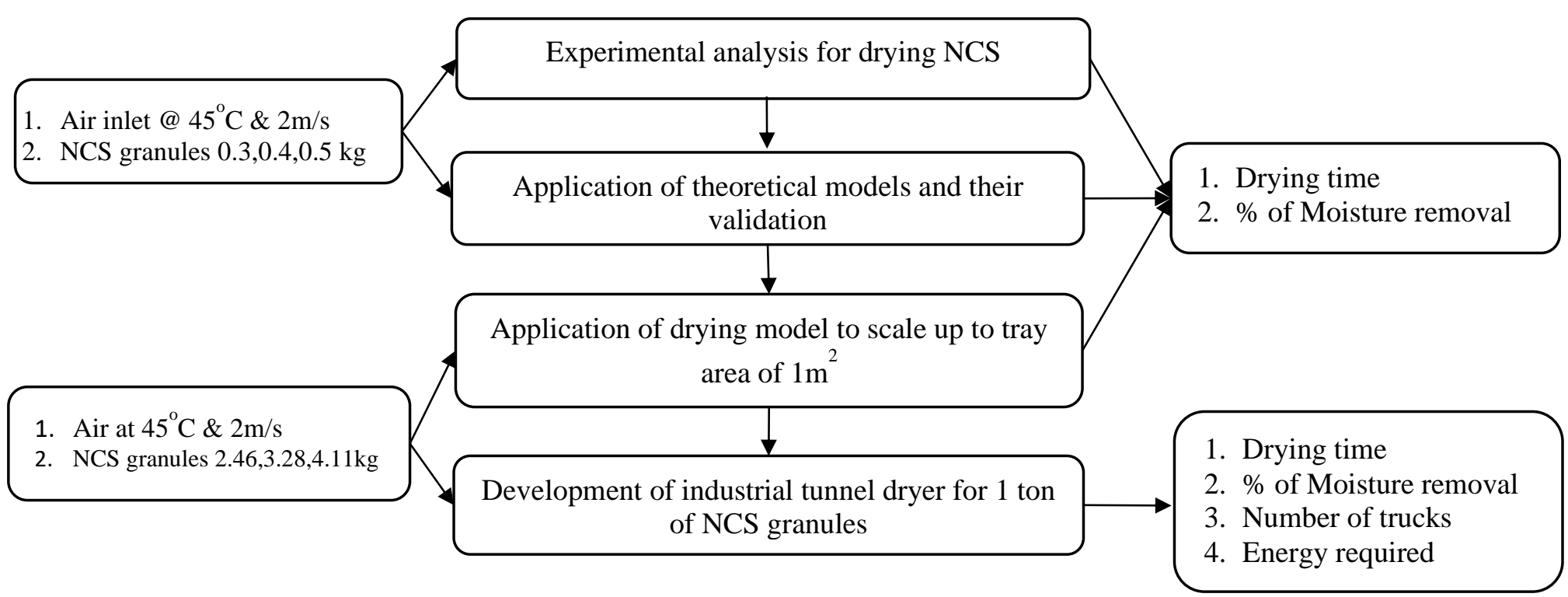

Figure 3. Methodology adopted for designing an industrial tunnel dryer.

\subsection{Experimental analysis for drying NCS}

Initially, the experimental analysis was carried out on a laboratory scale forced convective tray dryer with a tray area of $0.128 \mathrm{~m}^{2}$, to achieve the required moisture content in NCS granules and to determine the drying time. Figure 4 represents the laboratory scale forced convective tray dryer. The dryer is attached with the mass balance that ranges from 0 to $10 \mathrm{~kg}$ to measure the change in mass of the material placed in the tray. It is also equipped with necessary software and hardware support for data acquisition related to a reduction in mass with respect to time. The tray with NCS was covered with an empty tray of the same area at a distance of $0.05 \mathrm{~m}$ to form an air duct and mimic the configuration in the real dryer with a number of trays and trucks. The hot air required for drying the NCS granules is supplied by means of blower and heater mounted at one end and along the air duct respectively. Air temperature and velocity are the most important factors that influence the drying rate during the drying process [19]. The temperature of air considered for the drying process should not exceed the glass transition temperature of NCS which is $45^{\circ} \mathrm{C}$, beyond which the NCS granules will fuse [20]. The air velocity beyond $2 \mathrm{~m} / \mathrm{s}$ has no significant effect on the drying rate [21]. Therefore, inlet parameters such as velocity and temperature of the air to achieve required moisture content in NCS are considered to be $2 \mathrm{~m} / \mathrm{s}$ and $45^{\circ} \mathrm{C}$ respectively. 


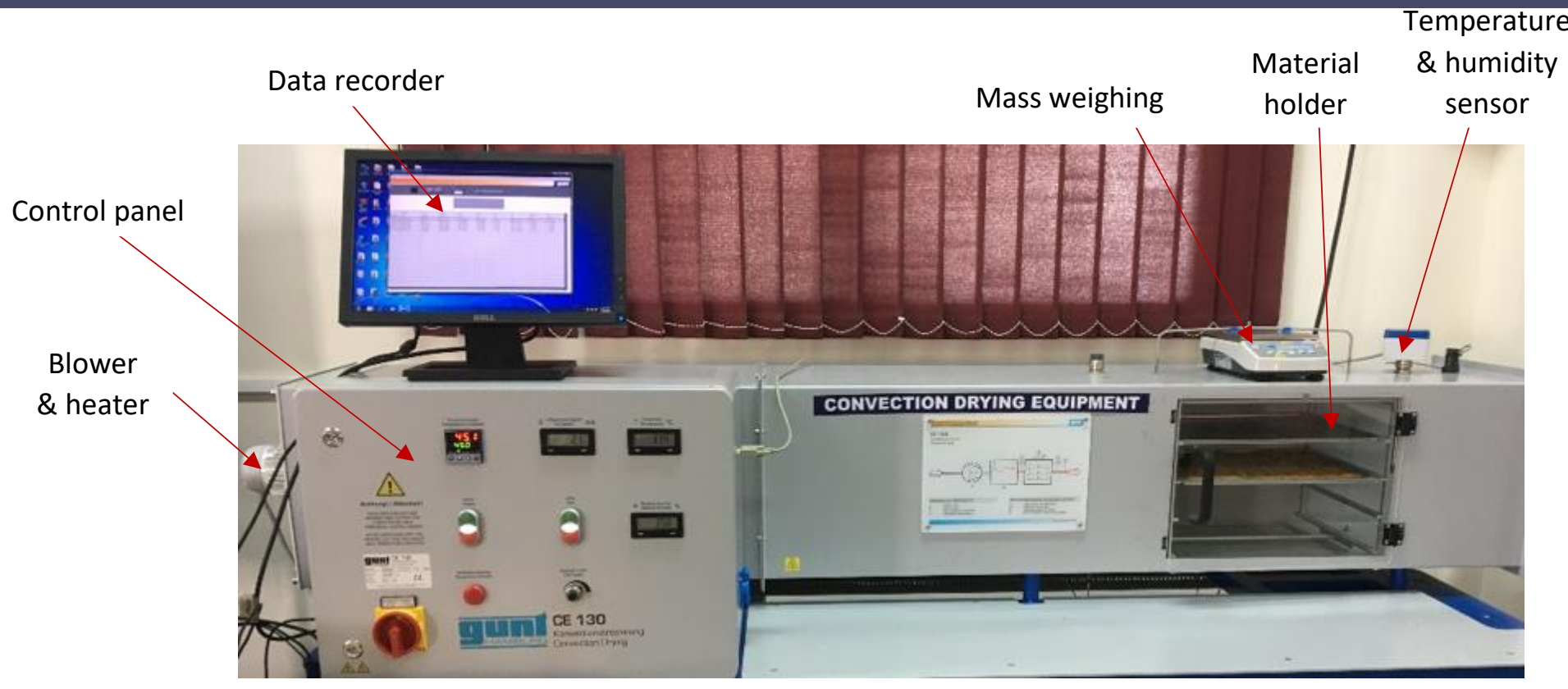

Figure 4. Laboratory scale forced convective tray dryer

For the experimental study, the NCS samples were sourced from an NCS plant at Erode, Tamil Nadu, India. The initial moisture content of these samples is $4.57 \%$. The study was carried out for various loads of NCS samples from $0.3 \mathrm{~kg}$ to $0.5 \mathrm{~kg}$ with an increment of $0.1 \mathrm{~kg}$ on a $0.128 \mathrm{~m}^{2}$ tray. These loads were selected since, NCS sample below $0.3 \mathrm{~kg}$ do not utilize the tray area completely and beyond $0.5 \mathrm{~kg}$ exceeds the drying time more than 1.5 hours (the drying time in current conventional process) and the selected $0.3 \mathrm{~kg}, 0.4 \mathrm{~kg}$ and $0.5 \mathrm{~kg}$ samples are distributed on the tray with the uniform thickness of $1.5,2 \& 2.5 \mathrm{~mm}$ respectively. Figure 5 shows the uniform distribution of the NCS sample on a tray area of $0.128 \mathrm{~m}^{2}$.

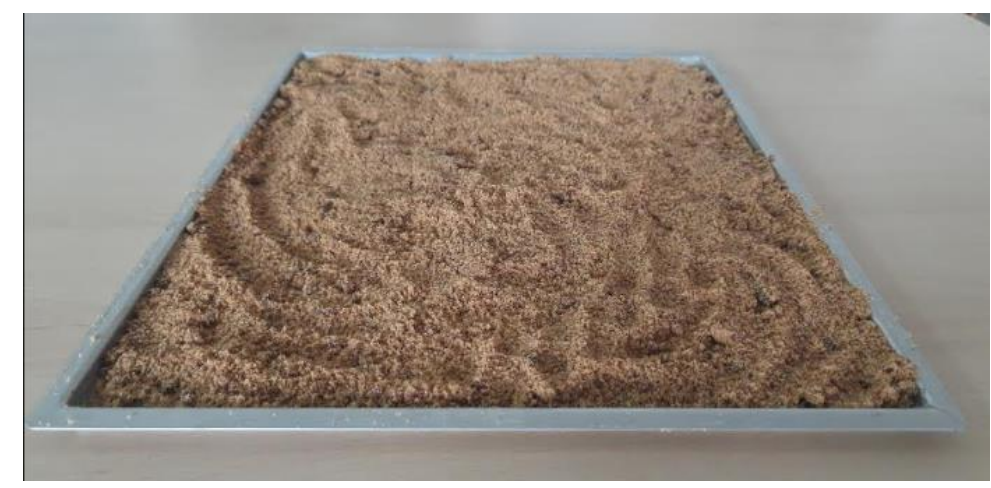

Figure 5. Uniform distribution of NCS sample on a tray area of $0.128 \mathrm{~m}^{2}$

The moisture content of the NCS sample was found to be $4.57 \%$ using the thermogravimetric analyser, which should be reduced to $3 \%$. In the process of drying, removal of moisture from the surface and also from the interior of the material is essential, in which drying rate plays a key role [22]. The percentage of moisture removed is assessed by weighing the samples for every 30 seconds. Further, the drying rate is computed by equation 1 . 


$$
\dot{m}=\frac{m_{i}-m_{f}}{t}
$$

where $m_{i}$ is the mass of the NCS sample before drying, $m_{f}$ is the mass of the NCS sample after drying and $t$ is the drying time.

\subsection{Theoretical drying models and their validation}

To make use of the data obtained through the experiments to get a generalized theoretical model that could be used for the design of an industrial dryer, the following two theoretical models were considered to obtain percentage moisture removal rates.

Model I: Figure 6 represents a typical drying curve applicable to granules. The initial moisture reaches critical moisture at a constant rate of drying during the constant rate period represented by $\mathrm{CB}$. The stage $\mathrm{CE}$ represents the falling rate period, during which the moisture reaches equilibrium moisture content and the drying rate is directly proportional to the moisture content [23] [24].

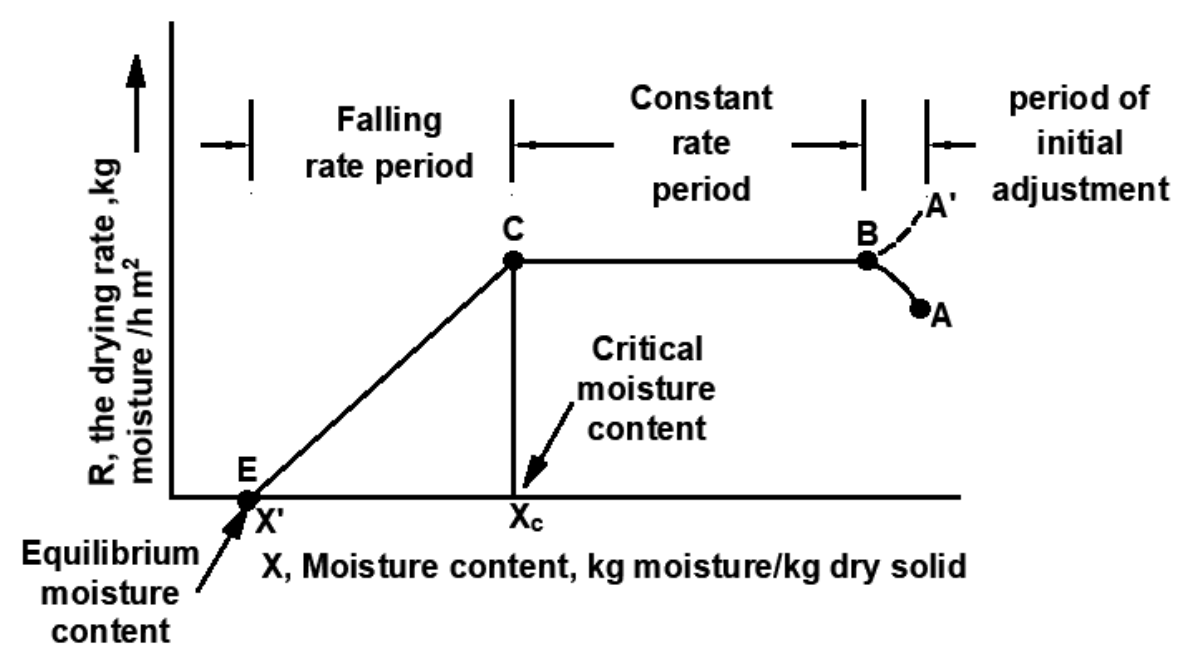

Figure 6. Drying rate curve for a constant drying condition [24]

As explained, in the results and discussions section, the experimental data when looked in conjunction with the drying rate curve can be observed that the drying of NCS comes under the falling rate period. Under these conditions, the following classical equation (equation 2) suggested by Dincer [23] could be used for obtaining the drying time $\left(\mathrm{d}_{\mathrm{t}}\right)$.

$$
\text { Drying time }\left(d_{t}\right)=\frac{m_{N C S}\left(X_{C}-X_{1}\right) h f g}{h\left(T_{\infty}-T_{i}\right)} \ln \left(\frac{X_{C}-X 1}{\mathrm{X}-X 1}\right)
$$

For this model, the drying time mainly depends on the mass of NCS $\left(\mathrm{m}_{\mathrm{NCS}}\right)$, critical moisture content $\left(\mathrm{X}_{\mathrm{C}}\right)$, equilibrium moisture content $\left(\mathrm{X}_{1}\right)$, instantaneous moisture content $(\mathrm{X})$ and the size of air duct. The critical moisture content $\left(\mathrm{X}_{\mathrm{C}}\right)$ and equilibrium moisture content $\left(\mathrm{X}_{1}\right)$ can be obtained from the previous experimental results carried on by forced convection dryer. The 
values of instantaneous moisture content $(\mathrm{X})$ could be the intermediate values between critical moisture content to equilibrium moisture content. The length (l) and width (b) of the duct could be considered to be the same as the laboratory tray dimensions $(0.4 \& 0.32 \mathrm{~m})$. Similarly, the height (a) could be taken as the distance between the trays $(0.05 \mathrm{~m})$.

Model II: As an alternative to the first model, in this second model, NCS with moisture in it could be considered as a lump which in turn suggests that the drying time could be calculated based on equation 3 .

$$
\text { Drying time }\left(d_{t}\right)=\frac{\left(m_{N C S}+m_{w j}\right) C_{N C S}}{h A} \ln \left(\frac{T_{i}-T_{\infty}}{T(t)-T_{\infty}}\right)
$$

For this model, the heat transfer coefficient can be determined by considering the rate of air mass flux (G, which ranges from 2450 to $29300 \mathrm{~kg} / \mathrm{hr}^{2} \mathrm{~m}^{2}$ ), as per the equation 4 .

$$
h=0.020 G^{0.8}
$$

Also, the drying time mainly depends on the mass of NCS $\left(\mathrm{m}_{\mathrm{NCS}}\right)$, equivalent mass of moisture in terms of NCS $\left(\mathrm{m}_{\mathrm{wj}}\right)$, area of the tray and the temperature of NCS at a particular time T(t). The equivalent mass of moisture in terms of NCS can be estimated based on the energy balance as per the equation 5 .

$$
m_{w} h_{f g}=m_{w j} C_{N C S}\left(T_{i}-T_{\infty}\right)
$$

Using the above two theoretical models, the drying time with respect to the percentage of moisture removal was computed and the results are compared with the experimental results to ensure the applicability of these models for developing an industrial-scale dryer. As presented in the results and discussion sections, the comparison ensured that the theoretical model I could be used for the development of industrial-scale tunnel dryers.

\subsection{Industrial tunnel drier design using theoretical models}

The above verified theoretical model I is used to develop a tunnel dryer capable of drying 1 ton of NCS that brings down the moisture from $4.75 \%$ to $3 \%$ in an estimated time of around 1.5 hours (same as the drying time in conventional NCS plant). As depicted in Fig. 1, a two steps process is followed for this.

\subsubsection{Application of drying model I for tray area of $1 \mathrm{~m}^{2}$}

In the first step, the above theoretical model I was applied for of tray area of $1 \mathrm{~m}^{2}$, initially, to ensure the applicability of this theoretical model I. The NCS loads for $1 \mathrm{~m}^{2}$ tray are obtained by linearly transforming the loads used in experimental analysis. Accordingly, the NCS loads for $1 \mathrm{~m}^{2}$ tray area are $2.46,3.28 \& 4.11 \mathrm{~kg}$ with corresponding layer thicknesses of $1.5,2 \& 2.5 \mathrm{~mm}$ respectively. Similar to the experimental analysis, the temperature and velocity of air are 
considered to be $45^{\circ} \mathrm{C}$ and $2 \mathrm{~m} / \mathrm{s}$ respectively. Using this theoretical model $\mathrm{I}$, the drying time and percentage of moisture removal were then computed, and these results are compared with the experimental and theoretical results that are obtained with the tray area of $0.128 \mathrm{~m}^{2}$. As presented in the results and discussion sections, for the increased tray area, the results are in agreement with the results obtained with the tray area if $0.128 \mathrm{~m}^{2}$. Therefore, the same theoretical model I could be used for the development of industrial-scale tunnel dryers.

\subsubsection{Development of tunnel dryer}

The tunnel dryer is considered to be the improvement of the tray dryer. It contains multiple trucks with each truck having several trays as shown in figure 2. The main parameters to be arrived at, for this designing process, are (i) the number of trays that can be arranged in the dryer (ii) energy required for the drying process.

The number of trays to be accommodated in the dryer depends on the vertical and horizontal arrangement of trays. The horizontal arrangement of trays is called a truck and each truck has several trays arranged vertically one over the other with a gap of $0.05 \mathrm{~m}$ forming a duct to pass hot air over it. A typical tunnel dryer can accommodate a minimum of 5 to a maximum of 20 trucks with each truck having 24 trays [18]. The number of trucks to be arranged in the dryer also depends upon the exit air temperature of the dryer. The dryer exit temperature is found to be $42^{\circ} \mathrm{C}$ with the minimum truck arrangement ( 5 trucks), as per the equation 4 and 5 (when air at $45^{\circ} \mathrm{C}$ is passed at the inlet of the dryer). It is observed during the experimental analysis that required moisture removal (from $4.49 \%$ to $3 \%$ ) does not happen when the air temperature falls below $38^{\circ} \mathrm{C}$. Therefore, the three possible temperatures at the exit of drier could be $38^{\circ} \mathrm{C}, 40^{\circ} \mathrm{C}$ $\& 42^{\circ} \mathrm{C}$.

The air temperature at the inlet of the dryer increases the NCS granules temperature from $25^{\circ} \mathrm{C}$ by absorbing the moisture present in each truck. Due to this phenomenon, the air temperature decreases as it passes from one truck to other and the amount of moisture removed $\left(\mathrm{m}_{\mathrm{w}}\right)$ from the NCS will be vaporised. This decrease in air temperature at exist of each truck $\left(\mathrm{T}_{\mathrm{o}}\right)$ will be the inlet air temperature $\left(\mathrm{T}_{\mathrm{i}}\right)$ for the subsequent truck. The decrease in air temperature at exist of each truck can be estimated from energy balance as per equation 6 . The mass of the air $\left(\mathrm{m}_{\text {air }}\right)$ can be estimated from equation 7 . The required drying time to calculate the mass of the air could be computed by theoretical model I. The air flow area ( $\mathrm{A}_{\text {flow }}$ ), above 
the NCS in the tray can be estimated by using the length of the tray $(\mathrm{L}=1 \mathrm{~m})$ and the distance between the trays $(\mathrm{a}=0.05 \mathrm{~m})$.

$$
\begin{gathered}
m_{\text {air }} C_{\text {air }}\left(T_{i}-T_{o}\right)=m_{N C S} C_{N C S}\left(T_{i}-25\right)+m_{w} h_{f g}+m_{w} C_{p}\left(T_{i}-25\right) \\
m_{\text {air }}=\rho_{\text {air }} A_{\text {flow }} V_{\text {air }} d_{t}
\end{gathered}
$$

The actual number of trucks that can be accommodated in the dryer is equal to the number of trucks obtained when the outlet temperature of the last truck is equal to the final exit temperature of the dryer. Table 1 represents the nine cases of various combinations of 2.46,3.28 $\& 4.11 \mathrm{~kg}$ of NCS granules placed on each tray with various dryer exit air temperature viz. $38^{\circ} \mathrm{C}$ $40^{\circ} \mathrm{C} \& 42^{\circ} \mathrm{C}$.

Table 1. Different cases for drying 1 ton of NCS granules

\begin{tabular}{ccc}
\hline Case & $\begin{array}{c}\text { NCS power loaded on } \\
\text { each tray } \\
(\mathrm{kg})\end{array}$ & $\begin{array}{c}\text { Dryer exit temperature } \\
\left({ }^{\circ} \mathrm{C}\right)\end{array}$ \\
\hline C1 & 2.46 & 42 \\
C2 & 3.28 & 42 \\
C3 & 4.11 & 42 \\
C4 & 2.46 & 40 \\
C5 & 3.28 & 40 \\
C6 & 4.11 & 40 \\
C7 & 2.46 & 38 \\
C8 & 3.28 & 38 \\
C9 & 4.11 & 38 \\
\hline
\end{tabular}

To achieve optimum dryer design among these nine case, it is necessary to estimate energy for each case to dry 1 ton of NCS granules The total energy required for the drying 1 ton of NCS granules can be estimated by computing the energy required by the blower and heater for supplying air at inlet of $2 \mathrm{~m} / \mathrm{s}$ and $45^{\circ} \mathrm{C}$ respectively. The energy required by the blower ( $\mathrm{E}_{\text {blower, }}$ $\mathrm{kJ})$ and heater $\left(E_{\text {heater, }} \mathrm{kJ}\right)$, can be estimated from the following equations 8,9 with heater and blower efficiencies as $90 \%$ and $70 \%$ respectively [25].

$$
\begin{gathered}
E_{\text {Heater }}=m_{\text {air }} C_{\text {air }}\left(45-T_{\infty}\right) \eta_{\text {heater }} \\
E_{\text {blower }}=\frac{Q_{\text {air }} \Delta p}{\eta_{\text {blower }}}
\end{gathered}
$$

The air flow rate can be determined by taking into account the cross-sectional area of the tray, over which the air flows at a constant velocity. The optimum dryer design can be obtained 
based on the minimum energy required by the heater and blower and minimum drying time to remove moisture present in one tone of NCS granules.

\section{Results \& discussions}

The analysis associated with the design of an industrial tunnel was carried out based on earlier presented experimental data and the theoretical models. The following sections discuss the findings to design an optimum tunnel dryer for achieving the required moisture content in NCS.

\subsection{Experimental results}

The experimental analysis was carried out for various loads of NCS samples $(0.3,0.4 \&$ $0.5 \mathrm{kgs}$ of NCS granules) on a laboratory scale forced convective tray dryer of $0.128 \mathrm{~m}^{2}$ tray area. The percentage of moisture removed with respect to drying time was determined. The amount of moisture removed is estimated by weighing the sample for every 30 seconds. From figure $7 \& 8$, it is observed that the drying of the NCS sample is found to be in the falling rate period with average equilibrium moisture of $2.87 \%$. The time required for drying $0.3,0.4 \&$ $0.5 \mathrm{~kg}$ of NCS samples to reach equilibrium moisture content was found to be $42,65 \& 81$ minutes respectively. Also, the percentage of moisture removed is computed to be $30 \%, 35 \%$ and $40 \%$ respectively. It is also observed that the rate of drying decreases with an increase in a load of NCS samples on each tray.

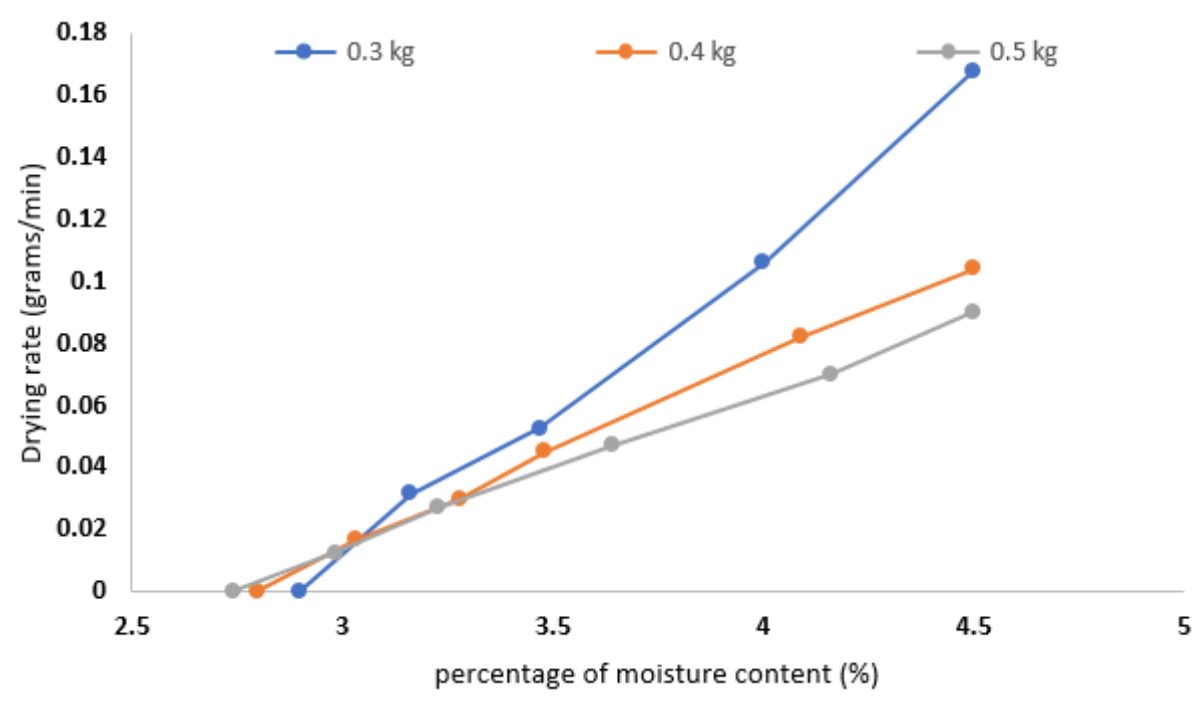

Figure 7. Percentage of moisture content w.r.t drying rate for varied mass of NCS 


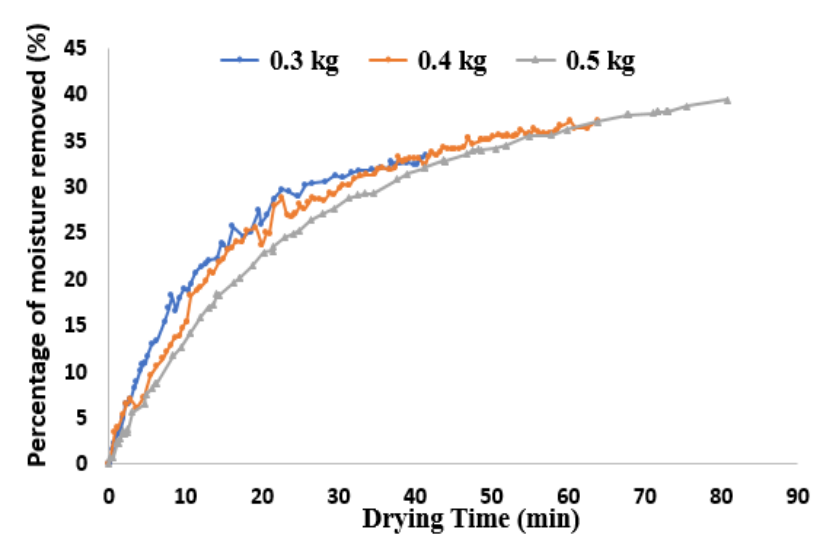

Figure 8. Percentage of moisture removal w.r.t drying time for the varied mass of NCS

\subsection{Validation of drying models with experimental results}

Drying models, I \& II presented earlier have been used to calculate the percentage of moisture removal with respect to drying time with the same air inlet conditions considered for the experimental analysis. From the figure 9, it is observed that the drying times required to reach equilibrium moisture content in $0.3,0.4 \& 0.5 \mathrm{~kg}$ of NCS samples are $42,65 \& 80$ minutes respectively with $30 \%$ of moisture removal as per the drying model I. Similarly, according to drying model II, the drying time required to reach equilibrium moisture content in $0.3,0.4 \& 0.5 \mathrm{~kg}$ of NCS granules was found to be $45,71 \& 90$ minutes respectively with $35 \%$ of moisture removal. These theoretical results indicate that the experimental results are consistent with drying model I. Also, it is observed that the result obtained by model II is exceeding the experimental results with percentage error ranging from 25 to $30 \%$. Therefore, model-I is considered for the design of an industrial dryer.

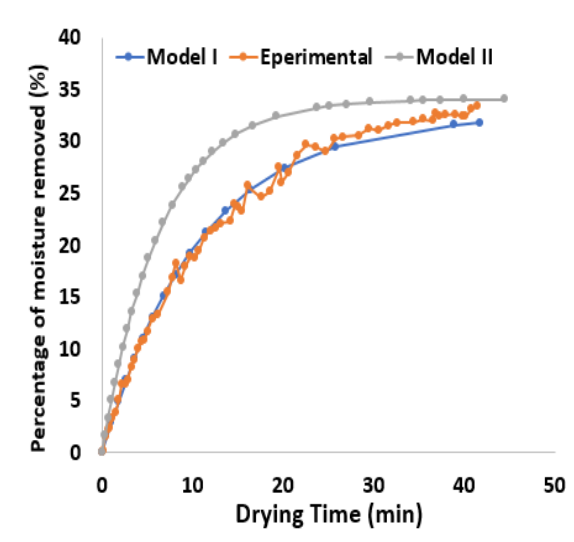

(a)

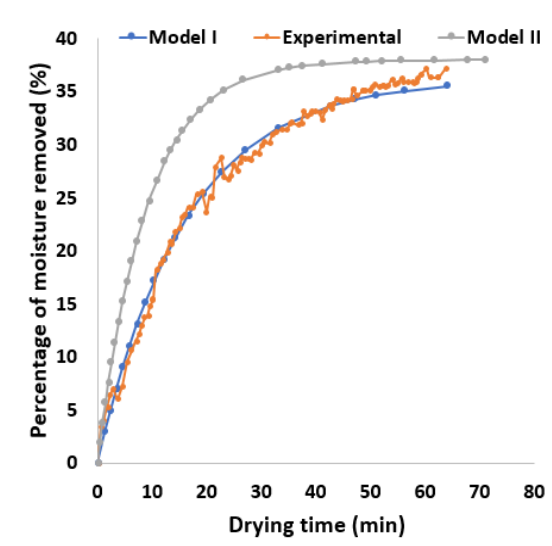

(b)

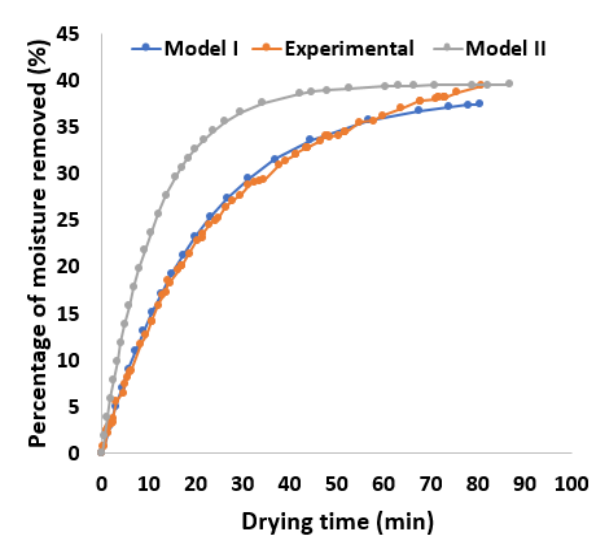

(c)

Figure 9. Comparison of theoretical analysis with experimental results for (a) $0.3 \mathrm{~kg}$ (b) $0.4 \mathrm{~kg}$ (c) $0.5 \mathrm{~kg}$ of NCS

\subsection{Scale up tray area of $1 \mathrm{~m}^{2}$ using drying models}


The drying model I was used to estimate the percentage of moisture removal with respect to drying time for the scale-up tray area of $1 \mathrm{~m}^{2}$ with the same air inlet conditions considered for the experimental analysis. According to this theoretical model, drying time and percentage of moisture removed for $2.46,3.28 \& 4.11 \mathrm{kgs}$ of NCS granules to reach equilibrium moisture content were found to be $42,64 \& 81$ minutes and $30,32 \& 35 \%$ respectively. From the figure 10 , it is observed that the drying time and percentage of moisture removed as predicted by the present theoretical model considered (for increased tray area) are in agreement with the results obtained from experiment and theoretical analyses for a tray area of $0.128 \mathrm{~m}^{2}$. Therefore, the same tray area and theoretical model I are considered for designing the optimum tunnel dryer for achieving the required moisture content in NCS granules.

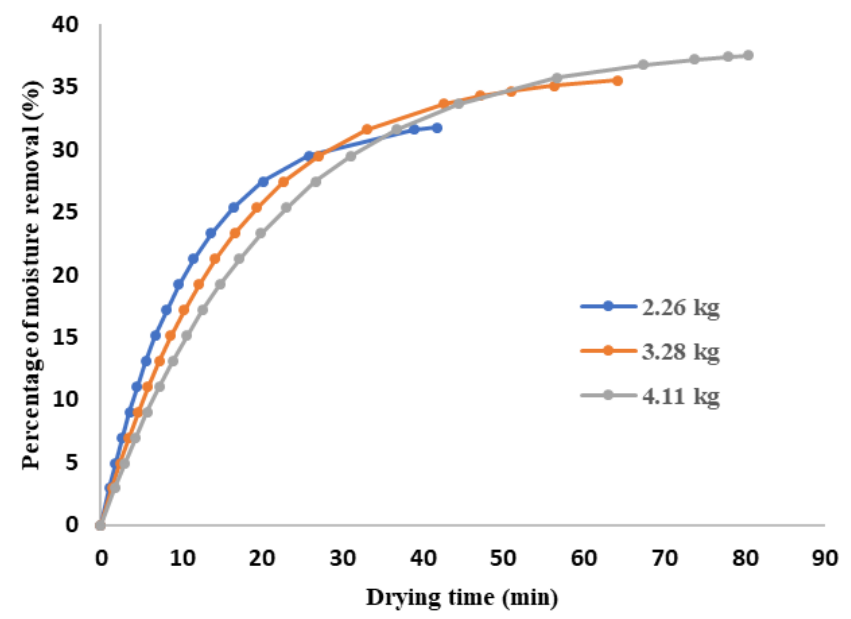

Figure 10. Theoretical analysis for scaled-up tray area of $1 \mathrm{~m}^{2}$

\subsection{Design of optimum dryer to achieve required moisture content in 1 ton of NCS granules}

The tunnel dryer is designed by estimating the number of trucks to be placed in a dryer and the total energy required for drying 1 ton of NCS granules. The number of trucks to be placed in the dryer is estimated by computing the drying time for various dryer exit temperature. The theoretical model I was used to compute the drying time with corresponding air temperatures at each truck and various NCS loads placed on each tray. Table 2 shows the drying time required, the number of trucks to be placed and the holding capacity of the dryer for various cases. Drying time is found to be minimum at $42^{\circ} \mathrm{C}$ dryer exit temperature with $2.46 \mathrm{~kg}$ of NCS granules loaded on each tray having 295.2 holding capacity. It is also estimated that a maximum 
of 18 trucks are required when each tray is loaded with $3.38 \mathrm{~kg}$ of NCS granules at $38^{\circ} \mathrm{C}$ dryer exit temperature.

Table 2. Different cases for drying NCS w.r.t to Model I

\begin{tabular}{cccccc}
\hline Case & $\begin{array}{c}\text { NCS power loaded on } \\
\text { each tray } \\
(\mathrm{kg})\end{array}$ & $\begin{array}{c}\text { Dryer exit } \\
\text { temperature } \\
\left({ }^{\circ} \mathrm{C}\right)\end{array}$ & Number of trucks & $\begin{array}{c}\text { Time } \\
(\mathrm{min})\end{array}$ & $\begin{array}{c}\text { Holding } \\
\text { capacity of the } \\
\text { dryer }(\mathrm{kg})\end{array}$ \\
\hline C1 & 2.46 & 42 & 5 & 55.02 & 295.2 \\
$\mathrm{C} 2$ & 3.28 & 42 & 6 & 56.12 & 472.3 \\
$\mathrm{C} 3$ & 4.11 & 42 & 6 & 61.60 & 591.8 \\
C4 & 2.46 & 40 & 10 & 74.29 & 590.4 \\
C5 & 3.28 & 40 & 11 & 83.82 & 865.9 \\
C6 & 4.11 & 40 & 11 & 96.48 & 1085.2 \\
C7 & 2.46 & 38 & 15 & 93.60 & 885.6 \\
C8 & 3.28 & 38 & 18 & 105.98 & 1416 \\
C9 & 4.11 & 38 & 17 & 119.20 & 1676.8 \\
\hline
\end{tabular}

It is also observed that the drying time and the number of trucks are comparatively higher when the dryer exit temperature is at $38^{\circ} \mathrm{C}$. Similarly, the drying time and the number of trucks are relatively minimum when the dryer exit temperature is at $42^{\circ} \mathrm{C}$. Figure 11 , shows the variation of temperature with respect to each truck. It is observed that temperature is uniformly decreasing from one truck to another truck in all the cases and the number of trucks is increasing with decreasing in the exit temperature of the dryer.

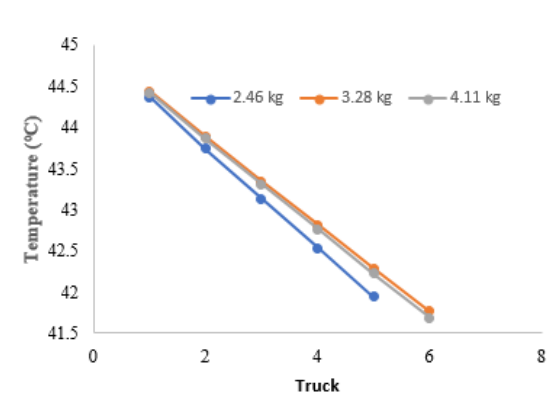

(a)

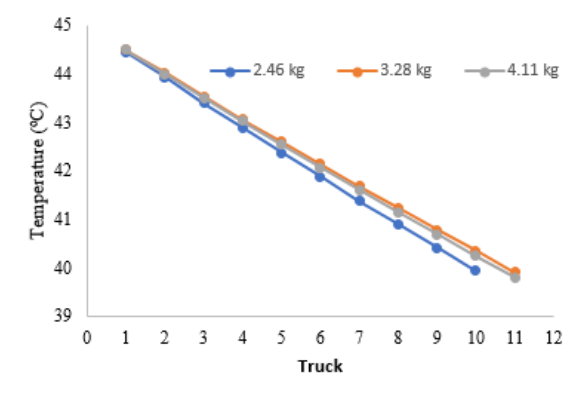

(b)

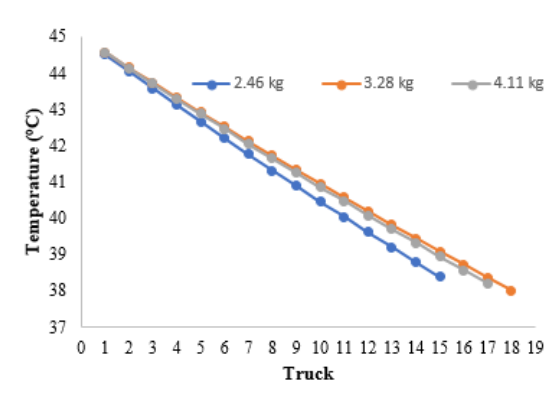

(c)

Figure 11. Temperature variation w.r.t each truck by model I for exit temperatures of air (a) $42^{\circ} \mathrm{C}$ (b) $40^{\circ} \mathrm{C}$ (c) $38^{\circ} \mathrm{C}$

Figure 12, shows the variation of drying time with respect to each truck. It is observed that, for a given number of trucks, as the mass of the NCS is increasing the drying time is increasing. The drying time is increasing progressively along the length of dryer indicating that the last truck is at lower temperature resulting in longer drying time for that truck, in comparison with the trucks at the entry. 


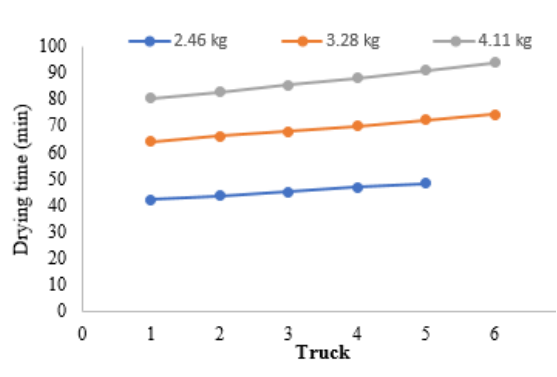

(a)

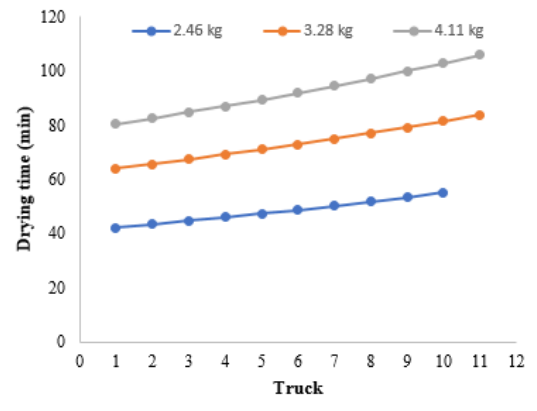

(b)

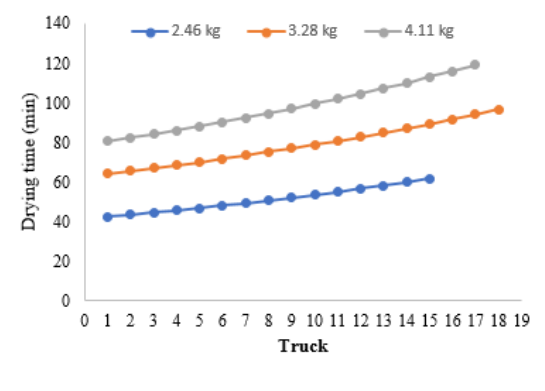

(c)

Figure 12. Drying time variation w.r.t each truck by model I for (a) $42^{\circ} \mathrm{C}$ (b) $40^{\circ} \mathrm{C}$ (c) $38^{\circ} \mathrm{C}$ exit temperatures

Further, the design parameters such as the length of the dryer and total energy required for drying 1 ton of NCS are estimated based on the above obtained results and the length of the dryer is estimated based on the number of trucks.

Figure 13 shows the total energy required for drying 1 ton of NCS granules for varied input conditions. It is observed that $150 \mathrm{KJ}$ of energy is required to blow the air at $2 \mathrm{~m} / \mathrm{s}$ and $45^{\circ} \mathrm{C}$ for case $1,2 \& 3$. That is the amount of energy required is minimum, when dryer exit temperature decreases to $38^{\circ} \mathrm{C}$ with $2.46,3.28 \& 4.11 \mathrm{kgs}$ of NCS granules loaded on each tray of 15,18 and 17 trucks respectively. It is also observed that $350-450 \mathrm{KJ}$ of energy is required for case $1,2 \& 3$. That is the amount of energy required is maximum, when dryer exit temperature decreases to $42^{\circ} \mathrm{C}$ with $2.46,3.28 \& 4.11 \mathrm{kgs}$ of NCS granules loaded on each tray of 5 and 6 trucks respectively.

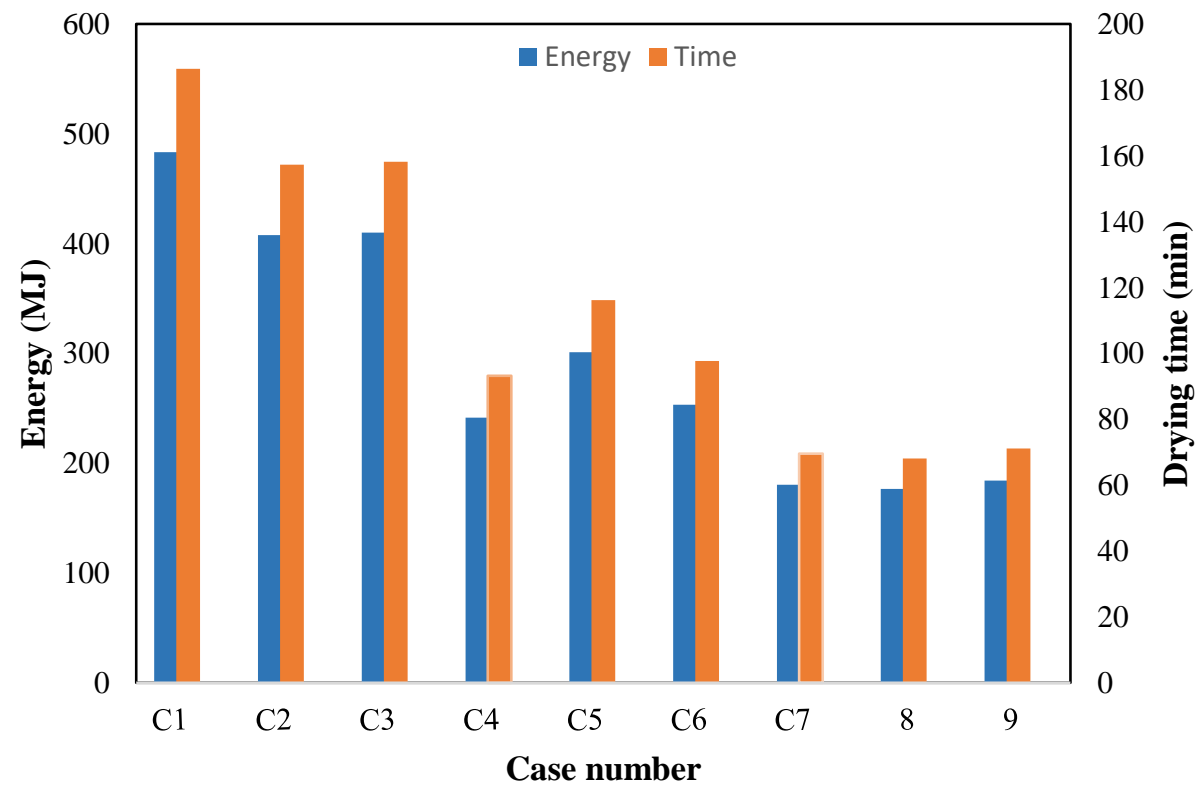

Figure 13. Energy required for drying 1 ton of NCS granules with respect to varied input conditions 
Therefore, based on the minimum energy required, the cases viz. C7, C8 \& C9 are considered for designing the optimum tunnel dryer to achieving the required moisture content in 1 ton of NCS granules. Table 3. show the three optimum tunnel dryer designs for drying one tone of NCS with air inlet temperature and velocity as $45^{\circ} \mathrm{C}$ and $2 \mathrm{~m} / \mathrm{s}$ respectively.

Table 3. Optimum tunnel dryer design

\begin{tabular}{ccccccc}
\hline Case & $\begin{array}{c}\text { Mass of NCS } \\
\text { granules loaded on } \\
\text { each tray }(\mathrm{kg})\end{array}$ & $\begin{array}{c}\text { Exit } \\
\text { temperature } \\
\left({ }^{\circ} \mathrm{C}\right)\end{array}$ & $\begin{array}{c}\text { Drying time } \\
(\mathrm{min})\end{array}$ & $\begin{array}{c}\text { Number of } \\
\text { trucks }\end{array}$ & $\begin{array}{c}\text { Energy } \\
(\mathrm{MJ})\end{array}$ & $\begin{array}{c}\text { Length of } \\
\text { the dryer } \\
(\mathrm{m})\end{array}$ \\
\hline C7 & 2.46 & 38 & 69.5 & 15 & 180.29 & 15 \\
C8 & 3.28 & 38 & 68 & 18 & 176.49 & 18 \\
C9 & 4.11 & 38 & 71.08 & 17 & 184.26 & 17 \\
\hline
\end{tabular}

Tunnel dryer of length $18 \mathrm{~m}$, height $1.2 \mathrm{~m}$ and width $1 \mathrm{~m}$ was found based on the minimum energy requirement of $176.49 \mathrm{MJ}$ and minimum drying time of 68 minutes to achieve the required moisture content of $3 \%$ in 1 tone of NCS granules (case 6). In this particular optimum case, the mass of NCS sample that can be loaded varies from $60 \mathrm{~kg}$ to $1085 \mathrm{~kg}$ with varying number of trays on each truck.

\section{Conclusions}

In the present paper, an attempt has been made to design a tunnel dryer to attain moisture content below 3\% in NCS granules. Initially, the experimental analysis was carried out on a laboratory scale forced convective tray dryer with a tray area of $0.128 \mathrm{~m}^{2}$ for various loads of NCS. During this experimental study, the drying of the NCS sample is found to be in the falling rate period with average equilibrium moisture of $2.87 \%$. It is also observed that the rate of drying is decreasing with an increase in a load of NCS samples on each tray. This experimental data is used for validating two drying models and found that one of the models is best suitable for designing an industrial-scale dryer. Nine different cases have arrived for various load conditions on each tray and dryer exit temperature. Tunnel dryer with a length of $18 \mathrm{~m}$, a height of $1.2 \mathrm{~m}$, a width of $1 \mathrm{~m}$, number of trucks of 18 and 24 number of trays on each truck was found to be the suitable dryer to dry 1 tone of NCS based on the minimum energy requirement of $176.49 \mathrm{MJ}$, and a minimum drying time of 68 minutes to achieve the require moisture content of $3 \%$ in 1 tone of NCS granules.

\section{Acknowledgements}

The research work presented in this paper is a part of "Sustainable technological solutions for energy efficiency in jaggery industry (STEEJ)" project, funded by Royal academy of 
Engineering (RAE) vide project reference \# IAPP1R2\100083. The authors gratefully acknowledge the RAE for funding this project.

\section{Reference}

[1] R. Kumar and M. Kumar, "Upgradation of jaggery production and preservation technologies," Renew. Sustain. Energy Rev.2018;96: 167-180.

[2] J. Singh, R. D. Singh, S. I. Anwar, and S. Solomon, "Alternative Sweeteners Production from Sugarcane in India: Lump Sugar (Jaggery),” Sugar Tech.2011;13(4): 366-371.

[3] M. Srinivas, B. Sravya, and S. P. Raj, "Crushing method selection for non-centrifugal sugar production by FAHP - ELECTRE I," Inter. J. low carbon tech.2020: 1-8.

[4] P. V. Sai and K. S. Reddy, “4-E ( Energy-Exergy-Environment-Economic ) analyses of integrated solar powered jaggery production plant with different pan configurations," Sol. Energy, vol. 2020; 197:126-143.

[5] F. Velásquez, J. Espitia, O. Mendieta, S. Escobar, and J. Rodríguez, "Non-centrifugal cane sugar processing: A review on recent advances and the influence of process variables on qualities attributes of final products," J. Food Eng.2019;255: 32-40.

[6] Chand, K., Shahi, N. C., Lohani, U. C., \& Garg, S. K. "Effect of storage conditions on keeping qualities of jaggery," Sugar Tech. 2011; 13(1):81-85.

[7] Uppal, S. K. "Storage of jaggery under low temperature for longer duration," Sugar Tech. 2002, 4(3-4): 177-178.

[8] D. P. Farooque, M., \& Srivastava, "A new physico-chemical concept of the hygroscopic property of gur (Jaggery).," in In Proc. II Bien. Conf, 1954, SRDW: 602-607.

[9] K. Y. Shiralkar, S. K. Kancharla, N. G. Shah, and S. M. Mahajani, "Energy improvements in jaggery making process," Energy Sustain. Dev.2014; 18(1): 36-48.

[10] Ramya, H. N., Gowda, M. C., Jayamala, G. B., Krishnamma, P. N., \& Shreedevi, M. S. "Effect of ambient atmospheric conditions on change in physico-chemical properties of stored jaggery," International Journal of Applied Agricultural Research 2010, 5(1):918.

[11] Prakash, O., \& Tiwari, G. N. "Empirical expressions for convective and evaporative heat transfer coefficients for the drying of concentrated sugar-cane juice," International journal of ambient energy 2005, 26(1):45-55.

[12] P. Taylor, O. Prakash, and A. Kumar, "Application of artificial neural network for the 
prediction of jaggery mass during drying inside the natural convection greenhouse dryer," International Journal of Ambient Energy, 2014 : 37-41.

[13] P. Jagannadha Rao, M. Das, and S. Das, "Jaggery - A Traditional Indian Sweetener," Indian J. Tradit. Knowl.2007; 6(1): 95-102.

[14] S. R. M. and G. C. DE D. MANDAL*, S. TUDU, "Effect of Common Packing Materials on Keeping Quality of Sugarcane Jaggery during Monsoon Season,” Sugar Tech. 2006; 8: 137-142.

[15] Chua, K. J., \& Chou, S. K. "Low-cost drying methods for developing countries," Trends in Food Science \& Technology 2003, 14(12):519-528.

[16] Suhaimi, Misha. "Review on the application of a tray dryer system for agricultural products," World applied sciences journal 2013, 22(3):424-433.

[17] Mabrouk, S. B., Khiari, B., \& Sassi, M. "Modelling of heat and mass transfer in a tunnel dryer," Applied thermal engineering 20016, 26(17-18):2110-2118.

[18] Kilpatrick, P. W., Lowe, E., \& Van Arsdel, W. B. "Tunnel dehydrators for fruits and vegetables," Advances in food research 1955, 6(360):60126-30.

[19] Krokida, M. K., Karathanos, V. T., Maroulis, Z. B., \& Marinos-Kouris, D. "Drying kinetics of some vegetables," Journal of Food engineering 2003, 59(4): 391-403.

[20] Jagannadha Rao, P. V., Das, M., \& Das, S. K. "Effect of moisture content on glass transition and sticky point temperatures of sugarcane, palmyra-palm and date-palm jaggery granules". International journal of food science \& technology 2010, 45(1):94104.

[21] R. N. Putra and T. A. Ajiwiguna, "Influence of Air Temperature and Velocity for Drying Process," Procedia Eng.2017;170: 516-519.

[22] Kumar, A., \& Tiwari, G. N. "Effect of shape and size on convective mass transfer coefficient during greenhouse drying (GHD) of jaggery," Journal of food engineering 2006, 73(2):121-134.

[23] Dinçer, İbrahim, and Calin Zamfirescu. Drying phenomena: theory and applications. John Wiley \& Sons, 2016.

[24] Geankoplis, Christie J. Transport processes and separation process principles:(includes unit operations). Prentice Hall Professional Technical Reference, 2003.

[25] Brkić, D. "An explicit approximation of Colebrook's equation for fluid flow friction factor," Petroleum Science and Technology 2011, 29(15):1596-1602. 